\title{
Topographic changes simulating keratoconus in patients with irregular inferior epithelial thickening documented by anterior segment optical coherence tomography
}

This article was published in the following Dove Press journal:

Clinical Ophthalmology

\author{
Mohamad El Wardani' \\ Kattayoon Hashemi' \\ Konstantinos Aliferis' \\ George Kymionis ${ }^{1,2}$ \\ 'Department of Ophthalmology, \\ University of Lausanne, Jules-Gonin Eye \\ Hospital, Foundation Asile des Aveugles, \\ Lausanne, Switzerland; ${ }^{2}$ Department of \\ Ophthalmology, 'G. Gennimatas \\ Hospital', National and Kapodistrian \\ University of Athens, Athens, Greece
}

\begin{abstract}
Purpose: To present six patients with keratoconus-like topographic changes due to inferior inhomogenous epithelial thickening, demonstrated by AS-OCT epithelium map.

Patients and methods: We present twelve eyes of six patients evaluated in the refractive surgery consultation with Pentacam ${ }^{\circledR}$ HR Scheimpflug rotating camera system, presenting topographical irregularities suggestive of keratoconus. Slit-lamp examination, best-corrected visual acuity, Scheimpflug tomography and anterior segment optical coherence tomography epithelium map (Optovue ${ }^{\circledR}$ ) were conducted and analyzed.

Results: The mean age was 42 years and the female:male ratio was 2:1. Mean Kmax was 45 $\pm 2 \mathrm{D}$. The mean corneal thickness at apex was $560 \pm 33 \mu \mathrm{m}$ and the mean thickness at the thinnest location was $555 \pm 34 \mu \mathrm{m}$. All patients had an abnormal index of height decentration (IHD) in at least one eye. In all cases, anterior segment OCT demonstrated relative epithelial thickening over the steep area measured by tomography. The mean thickness of the inferior epithelium over the suspicious area was $60 \pm 2 \mu \mathrm{m}$, whereas the mean thickness of the superior epithelium was $56 \pm 2 \mu \mathrm{m}$.

Conclusion: Epithelial irregularity, as measured by anterior segment OCT, should be considered as a possible contributing factor in the appearance of suspicious keratoconus-like topographies.

Keywords: pseudokeratoconus, epithelial hyperplasia, Pentacam, epithelial thickness, pachymetry
\end{abstract}

\section{Introduction}

Keratoconus $(\mathrm{KCN})$ is a non-inflammatory ectatic disorder that needs to be ruled out in every refractive surgery candidate in order to minimize the risk of postoperative ectasia. Corneal tomography is an essential tool to diagnose $\mathrm{KCN}$ during the preoperative evaluation. Multiple parameters on different maps help differentiate between normal and ectatic eyes. ${ }^{1}$ However, certain parameters such as focal steepening, increased astigmatism, abnormally increased anterior or posterior elevation may show an ectatic pattern in non-keratoconic eyes. ${ }^{2}$ Many factors could lead to misdiagnosis of keratoconus, including poor fixation, tear film instability, loss of corneal transparency and contact lens warpage. ${ }^{3-6}$ Consequently, additional screening methods at times are necessary to differentiate $\mathrm{KCN}$ from pseudokeratoconus.
Correspondence: Mohamad El Wardani Jules Gonin Eye Hospital, Faculty of Biology and Medicine, University of Lausanne, Avenue de France 15, Lausanne 1004, Switzerland

Tel +4I 216268226

Fax +4I 2I 6268246

Email elwardani@gmail.com 
The corneal epithelium is gaining popularity as an important screening tool for corneal ectatic diseases. ${ }^{7,8}$ Facing a stromal thickness variation, the corneal epithelium has the ability to adapt its thickness in order to maintain a smooth corneal surface. This might mask bulging conus in case of an already ongoing stromal thinning. ${ }^{9}$ In keratoconic patients, epithelial thinning over the conus surrounded by an annulus of thickened epithelium, the so called "Donut shape", has been documented by Reinstein et al using Artemis very high frequency ultrasound. $^{7}$ Whereas keratoconus is associated with epithelial thinning over the conic area, ${ }^{7,10}$ pseudokeratoconus may be associated with localized epithelial thickening, as illustrated in this paper.

\section{Patients and methods}

Subjects were recruited from the refractive surgery clinic at the Jules Gonin Eye Hospital, University of Lausanne, Switzerland. Assessment of all candidates included uncorrected visual acuity, manifest and cycloplegic refraction, slitlamp examination, intraocular pressure measurement, dilated fundus examination, corneal tomography using Scheimpflug imaging (WaveLight ${ }^{\circledR}$ OculyzerTM II, Germany) and epithelial thickness data using the anterior segment module of OCT (Optovue Avanti OCT, Fremont, California, USA). The inclusion criteria were any tomographic corneal abnormalities mimicking keratoconus associated with relatively thickened inferior epithelial pachymetry. All patients provided a written informed consent in accordance with the Declaration of Helsinki and the institutional guidelines. The study was approved by the ethics committee of the University of Lausanne and Jules Gonin University Eye Hospital. Patient identity was masked in all information tables and images.

\section{Results}

Twelve eyes of six candidates were evaluated. The mean age was 42 years, and the female:male ratio was 2:1. There was no history of allergy or eye rubbing in any of the patients. Three patients wore soft contact lenses which they discontinued at least 10 days prior to presentation. None of the patients demonstrated clinical signs of keratoconus by slit-lamp examination.

In all candidates, the tomography revealed irregular astigmatism, Mean Kmax was $45 \pm 2$ D. The mean corneal thickness at apex was $560 \pm 33 \mu \mathrm{m}$ and the mean thickness at the thinnest location was $555 \pm 34 \mu \mathrm{m}$ (Table 1). All patients had abnormal index of height decentration (IHD) in at least one eye. This index reflects the degree of vertical decentration of corneal elevation (abnormal value: $>0.014 \mu \mathrm{m}$, pathological value: $>0.016 \mu \mathrm{m}$ ). In all cases, AS-OCT demonstrated relative epithelial thickening over the steep area measured by tomography. The mean thickness of the inferior epithelium over the suspicious area was $60 \pm 2 \mu \mathrm{m}$, whereas the mean thickness of the superior epithelium was $56 \pm 2 \mu \mathrm{m}$. The mean I-S difference was $4 \mu \mathrm{m}$.

Figures $1(\mathrm{~A}-\mathrm{C})$ and $2(\mathrm{~A}-\mathrm{C})$ are representative illustrations of our case series, whereas Figure $3(\mathrm{~A}-\mathrm{C})$ refers to a patient who had PRK of the right eye 7 years prior to presentation.

The IOP in all patients was in the normal range. Retinal examination demonstrated attached retina in all eyes, without any peripheral abnormalities.

\section{Discussion}

Iatrogenic ectasia and loss of best-corrected vision are the most dreaded complication after LASIK. A major risk factor for iatrogenic ectasia is undiagnosed subclinical keratoconus. Meticulous preoperative screening enables the refractive surgeon to confidently rule out keratoconus in most cases. Advancement in diagnostic tools permits more accurate detection of ectatic conditions, even at very early stages. Analyses of the anterior and posterior corneal curvature and elevation data, pachymetric corneal and epithelial profiles as well as corneal biomechanical properties increase the accuracy of keratoconus detection. Nevertheless, there is still a possibility of false positive or false negative diagnosis of subclinical keratoconus. Incorrect patient positioning during measurement may lead to misalignment and consequently induce corneal asymmetry on elevation and curvature maps. ${ }^{2}$ Anterior corneal shape can be sometimes influenced by eyelid pressure, thus inducing anterior map inaccurate measures. ${ }^{11}$ Tear film instability due to dry eyes, ocular rosacea or contact lens wear can alter epithelial cell homeostasis and in turn lead to inaccurate tomographic data. ${ }^{5,6,12}$ Focal Descemet membrane disruption has been shown to induce an increase in focal corneal thickness, with resulting changes in pachymetric and tomographic patterns. ${ }^{13}$

AS-OCT is becoming an increasingly useful complementary tool in the screening of refractive surgery candidates. In normal subjects, many studies have shown a thinner epithelium superiorly with mean values between 44 and $52 \mu \mathrm{m}$ when compared to the inferior region with mean values between 52 and $54 \mu \mathrm{m} \cdot{ }^{14-16}$ In this case series, the overall epithelium thickness is slightly higher 
Table I Demographic, tomographic and epithelial thickness data

\begin{tabular}{|c|c|c|c|c|c|c|c|c|c|c|c|c|c|}
\hline Patient & Age & Sex & CL & $\begin{array}{l}\text { Stopped } \\
\text { CL }\end{array}$ & MGD & $K \max$ & $\begin{array}{l}\text { Mean } \\
\mathbf{K}\end{array}$ & $\begin{array}{l}\text { Corneal } \\
\text { thickness } \\
\text { apex }\end{array}$ & $\begin{array}{l}\text { Thinnest } \\
\text { pachymetry }\end{array}$ & $\begin{array}{l}\text { Epithelial } \\
\text { pachymetry } \\
\text { inferiorly }\end{array}$ & $\begin{array}{l}\text { Epithelial } \\
\text { pachymetry } \\
\text { superiorly }\end{array}$ & $\begin{array}{l}\text { Inf- } \\
\text { sup }\end{array}$ & $\begin{array}{l}\text { IHD } \\
\text { value }\end{array}$ \\
\hline I RE & 35 & $\mathrm{~F}$ & Soft & I0 Days & Yes & 47.1 & 46 & 606 & 600 & 61 & 56 & 5 & 0.02 \\
\hline I LE & 35 & $\mathrm{~F}$ & Soft & 10 Days & Yes & 47.3 & 46.1 & 617 & 616 & 60 & 58 & 2 & 0.021 \\
\hline $2 \mathrm{RE}$ & 27 & $\mathrm{~F}$ & Soft & 10 Days & Yes & 44.8 & 44 & 537 & 526 & 62 & 57 & 5 & 0.021 \\
\hline $2 \mathrm{LE}$ & 27 & $\mathrm{~F}$ & Soft & I0 Days & Yes & 45.5 & 44.3 & 548 & $54 I$ & 61 & 56 & 5 & 0.014 \\
\hline $3 \mathrm{RE}$ & 54 & $M$ & Soft & 10 Days & Yes & 43.6 & 42.6 & 545 & 540 & 61 & 60 & I & 0.017 \\
\hline 3 LE & 54 & $M$ & Soft & 10 Days & Yes & 43.3 & 42.8 & 544 & 539 & 59 & 57 & 2 & 0.01 \\
\hline $4 \mathrm{RE}$ & 26 & $\mathrm{~F}$ & Soft & 10 Days & & 43 & 42.1 & 574 & 571 & 58 & 53 & 5 & 0.02 \\
\hline $4 \mathrm{LE}$ & 26 & $\mathrm{~F}$ & Soft & 10 Days & & 42.6 & 41.9 & 584 & 579 & 56 & 52 & 5 & 0.015 \\
\hline $5 \mathrm{RE}$ & 50 & $\mathrm{~F}$ & Non & & & 44.8 & 43.9 & 565 & 563 & 59 & 54 & 5 & 0.007 \\
\hline 5 LE & 50 & $\mathrm{~F}$ & Non & & & 45.9 & 44.3 & 569 & 568 & 63 & 57 & 6 & 0.018 \\
\hline $6 \mathrm{RE}$ & 59 & $M$ & Non & & Yes & 46.5 & 45.3 & 497 & 494 & 64 & 56 & 8 & 0.013 \\
\hline $6 \mathrm{LE}$ & 59 & $M$ & Non & & Yes & 46.7 & 45.3 & 533 & 525 & 62 & 57 & 5 & 0.026 \\
\hline Mean & 41.83 & & & & & 45.09 & 44.05 & 559.92 & 555.17 & 60.5 & 56.08 & 4.42 & 0.02 \\
\hline SD & 13.66 & & & & & 1.66 & 1.46 & 33.16 & 34.31 & 2.07 & 2.19 & 1.93 & 0.01 \\
\hline Min & 26.00 & & & & & 42.60 & 41.90 & 497.00 & 494.00 & 57.00 & 52.00 & 1.00 & 0.01 \\
\hline Max & 59.00 & & & & & 47.30 & 46.10 & 617.00 & 616.00 & 64.00 & 60.00 & 8.00 & 0.03 \\
\hline
\end{tabular}

Abbreviations: I, inferior; S, superior; CL, contact lens; MGD, meibomian gland dysfunction.

than in previous studies (superior mean $=56 \mu \mathrm{m}$ and inferior mean $=60 \mu \mathrm{m})$. Furthermore, the (S-I) mean difference in normal corneal epithelium has been shown to be between 2 and $5 \mu \mathrm{m} .{ }^{17}$ In this series, the difference between mean superior and inferior epithelial thickness was shown to be about $4 \mu \mathrm{m}$, which is in agreement with previous studies.

In keratoconus patients, epithelial thinning has been demonstrated with the aid of AS-OCT. ${ }^{17-19}$ Furthermore, using Artemis very-high frequency digital ultrasound, Reinstein et al have demonstrated epithelial thinning overlying the apex of a cone with surrounding epithelial thickening in a Donut pattern. ${ }^{7}$ In the cases presented here, in contrast to epithelial thinning and Donut shape formation, AS-OCT revealed relative inferior epithelial thickening overlying the steep area, with mean values of $60 \mu \mathrm{m}$.

Herein, we include tomography and epithelial maps of six representative cases where tomography appeared suspicious for subclinical keratoconus yet epithelial maps revealed epithelial thickening in the suspicious zone (Figures 1 and 2). Through these cases, we attempt to highlight the importance of the epithelium in the diagnosis of pseudo keratoconus. In five cases, anterior sagittal maps revealed irregular astigmatism with inferior steepening and topometric maps showed IHD irregularities in at least one eye. The IHD is considered to be one of the most sensitive and specific criteria in the diagnosis and follow-up of keratoconus. ${ }^{1}$ It is calculated on a ring with radius of 3 $\mathrm{mm}$ and represents the degree of height decentration in the vertical direction. A value of more than $0.014 \mu \mathrm{m}$ is considered borderline, and more than $0.016 \mu \mathrm{m}$ is pathological.

When considering tomographic examination alone, these subjects would be considered keratoconus suspects or having subclinical keratoconus according to the keratoconus grading scheme suggested by the Collaborative Longitudinal Evaluation of Keratoconus Study group. ${ }^{20}$ However, AS-OCT revealed epithelial irregularity with relative thickening inferiorly corresponding to the steep area measured by the Oculyzer tomographer. In the case 7 years post PRK, the one eye which was operated did not develop ectasia even though the fellow eye had suspicious appearing tomography and epithelial thickening, illustrating that most likely the patient does not have subclinical keratoconus (Figure 3).

We postulate that the relative epithelial thickening noted in our subjects may be due to factors such as dry eyes and exposure, tear film abnormality or contact lens warpage. Regarding dry eyes and epithelial thickness, there are conflicting reports in the literature. With the aid of Fourier-domain OCT, epithelium has been measured to be significantly thicker, thinner or not significantly different from normal eyes. Cui et al demonstrated that the epithelium was thinner superiorly relative to normal eyes with significantly thinner minimum epithelium and greater range of map standard deviation, ${ }^{21}$ whereas Francoz et al 
WAVELIGHT - ALLEGRO OCULYZER Topometric

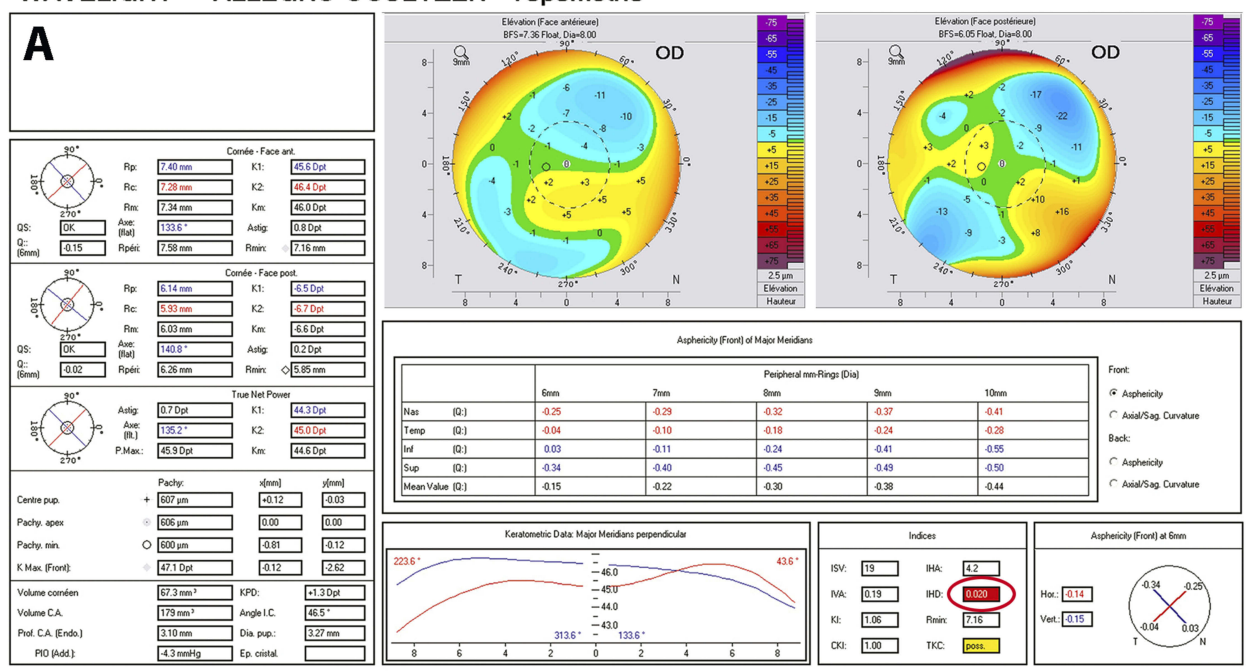

WAVELIGHT - ALLEGRO OCULYZER Topometric

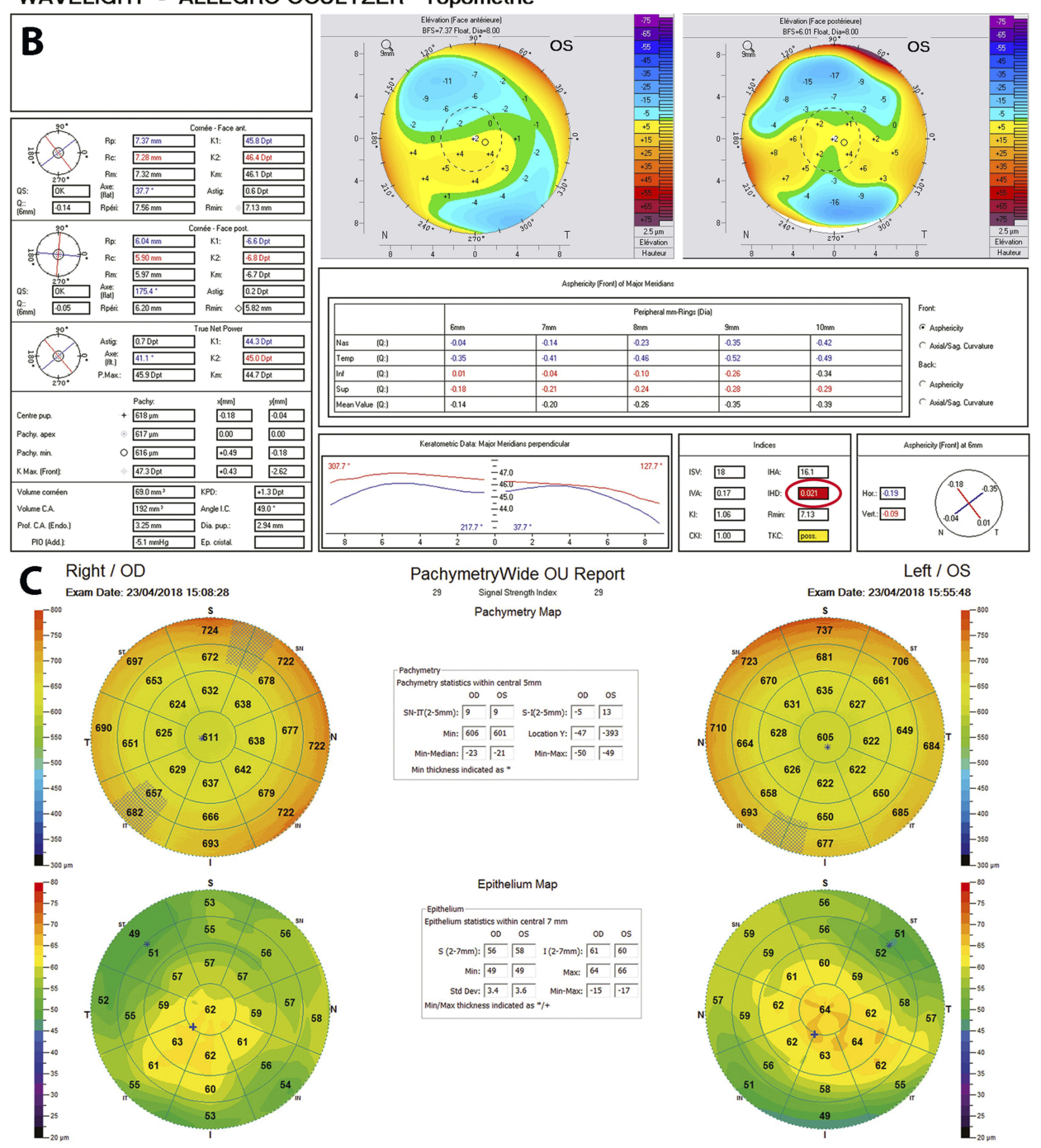

Figure I (A and B) Topometric map of the right and left eye of one patient. Note the abnormal IHD and the borderline keratoconus classification in both eyes. (C) Epithelial map of the right and left eye of the same patient; note the relative epithelial thickening inferiorly corresponding to the steep areas noted in $\mathbf{A}$ and $\mathbf{B}$. 


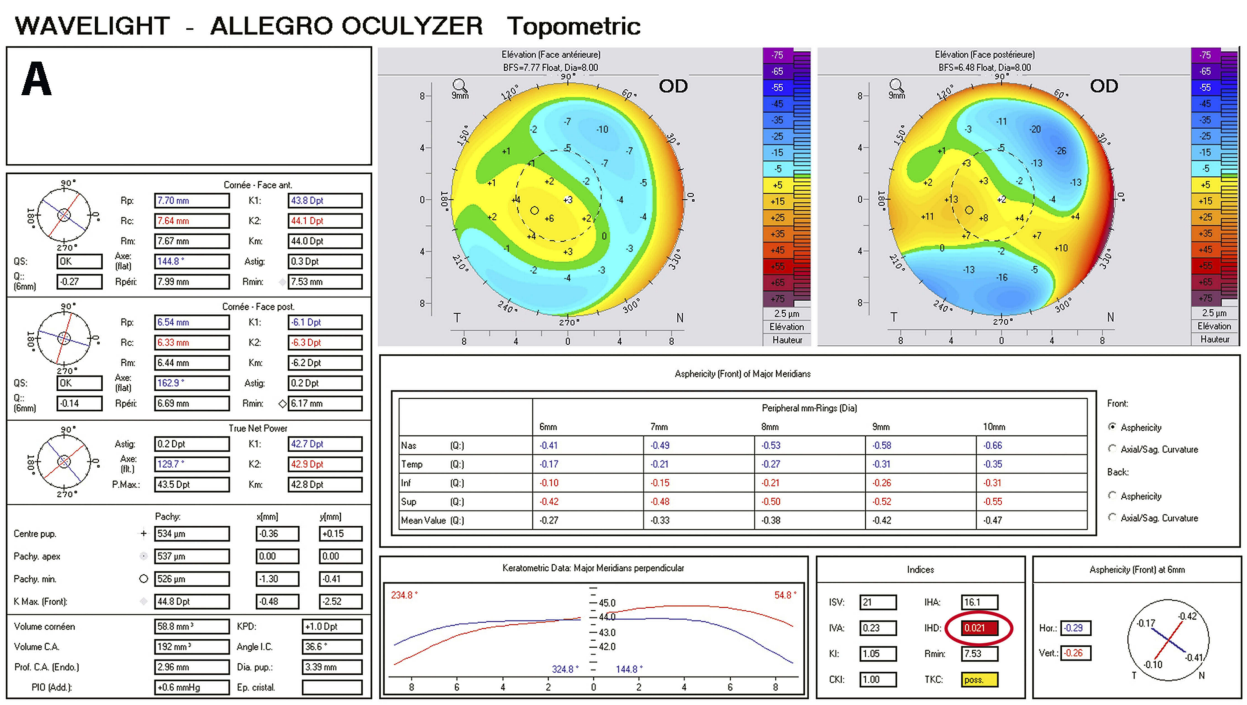

WAVELIGHT - ALLEGRO OCULYZER Topometric
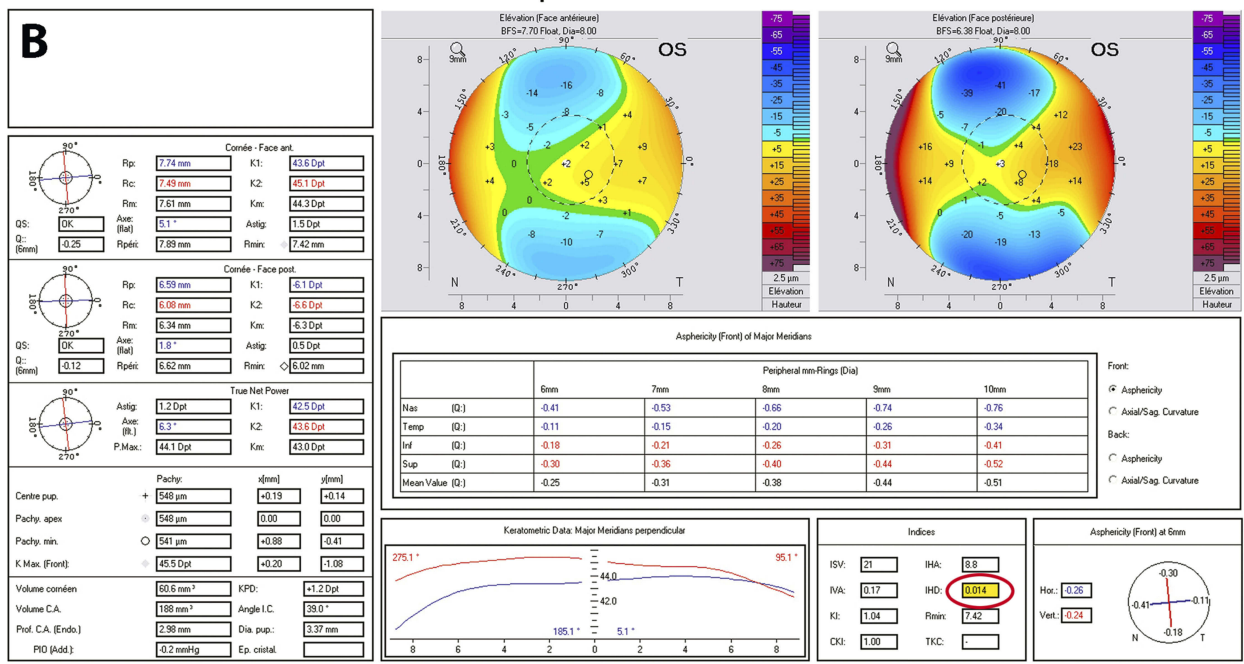

C Right / OD

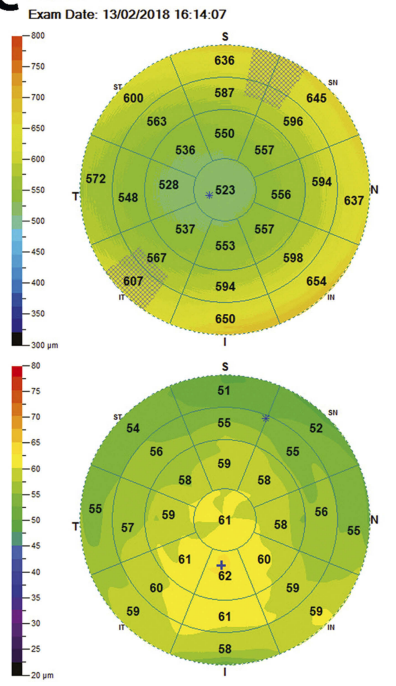

PachymetryWide OU Report

32 Signal Stronghindex

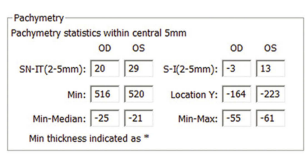

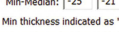

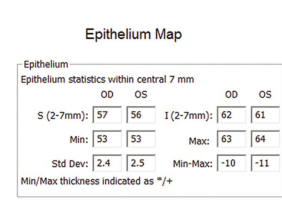

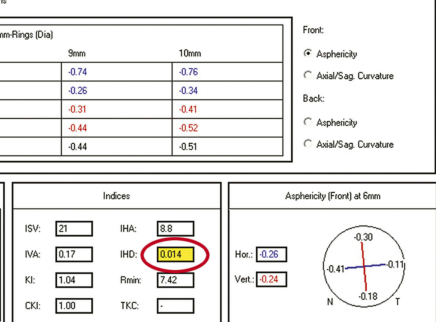

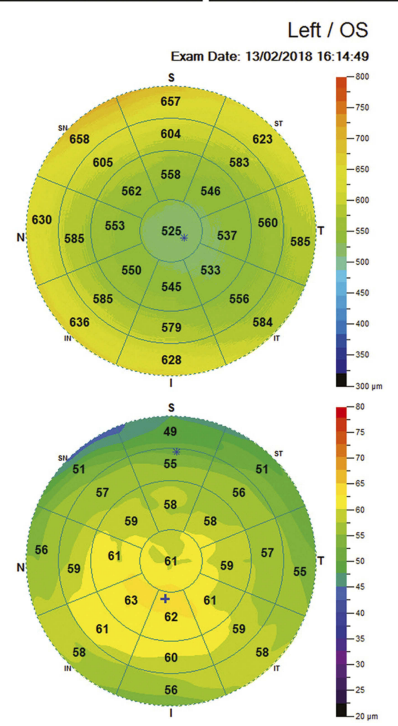

Figure 2 ( $\mathbf{A}$ and $\mathbf{B}$ ) Topometric map of the right and left eye of another patient. Note the abnormal IHD in both eyes, and the borderline keratoconus classification in right eyes. (C) Epithelial pachymetry map of both eyes of the second patient. Note the relative epithelial thickening inferiorly corresponding to the steep areas noted in $\mathbf{A}$ and $\mathbf{B}$. 
WAVELIGHT - ALLEGRO OCULYZER Topometric
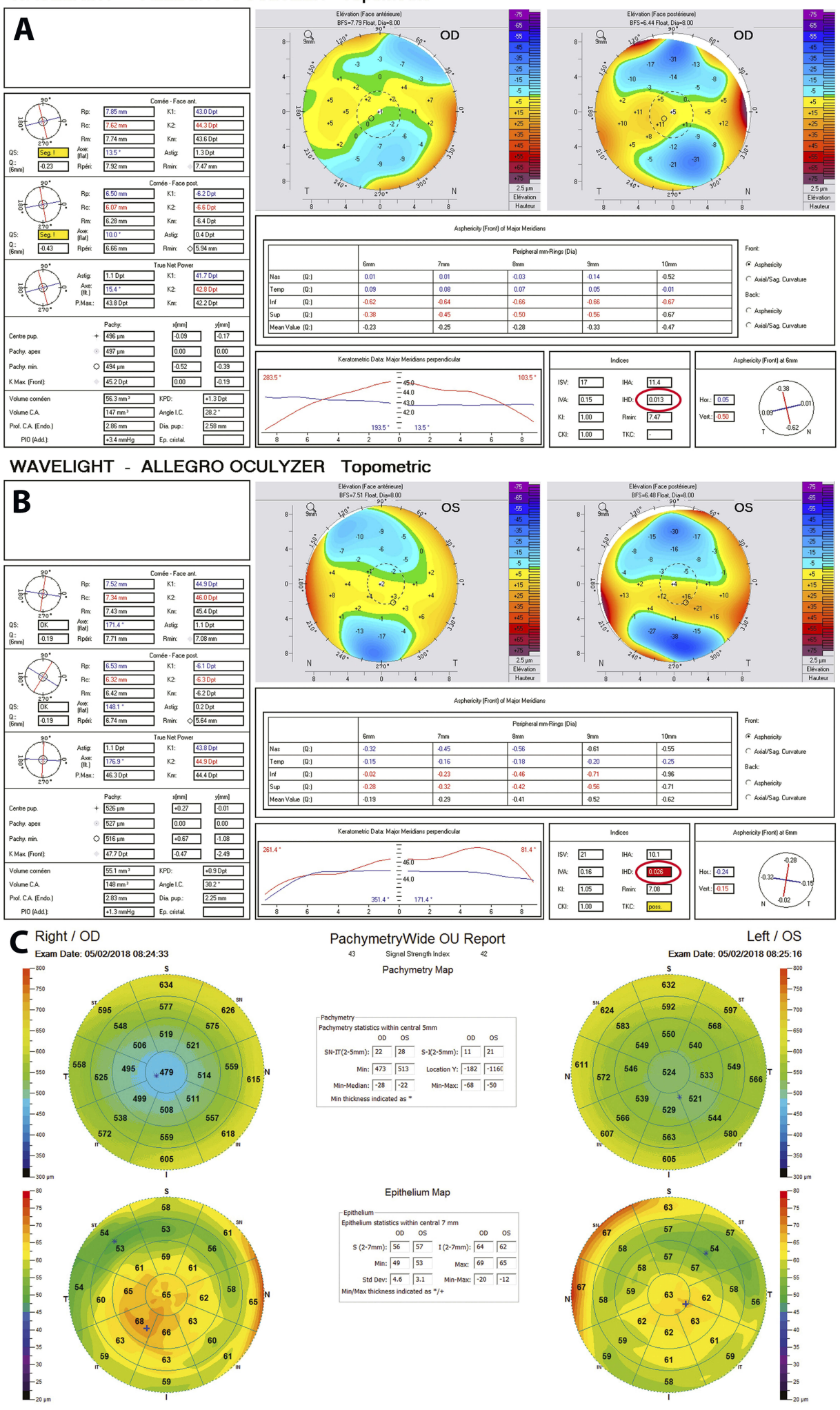

Figure 3 (A and B) Topometric map of the right and left eye, 7 years post PRK of the right eye. (C) Epithelial pachymetry map of both eyes. Note the relative epithelial thickening inferiorly corresponding to the steep areas noted in $\mathbf{A}$ and $\mathbf{B}$. 
found no significant difference between dry eye and normal patients. ${ }^{22}$

Another possible explanation for the epithelial irregularity seen in some of our cases is corneal warpage, which is described to be commonly associated with irregular epithelium. Focal topographic steepening with epithelial thickening and/or focal topographic flattening with epithelial thinning has been reported. ${ }^{23}$ In our case series, however, half of our patients did not wear contact lenses and the remaining patients discontinued soft contact lens wear at least 10 days prior to the screening examination.

Additional explanation for the epithelial irregularity is subclinical anterior basement dystrophy. However, this is unlikely since none of our patients had slit-lamp evidence of this dystrophy and AS-OCT did not reveal any hyperreflectivity in the posterior epithelium and anterior stroma as reported by Peter $\mathrm{Wu}$ et al or presence of intraepithelial basement membrane, inclusions or anterior stromal hyper-reflectivity as reported by Diez-Feijóo and Durán. ${ }^{24,25}$

This study has some limitations, mainly the small number of cases. However, it highlights the synergistic role of epithelial thickness maps and tomography to rule out subclinical keratoconus in refractive surgery candidates. The fact that the relative epithelial thickening corresponds to the suspicious zone on tomography is an interesting observation which therefore merits further investigation with larger number of cases.

To our knowledge, this is the first reported case series demonstrating the importance of AS-OCT in illustrating the role of corneal epithelial tomographically suspicious profile in corneas of refractive surgery candidates.

\section{Disclosure}

The authors report no conflicts of interest in this work.

\section{References}

1. Shajari M, Jaffary I, Herrmann K, et al. Early tomographic changes in the eyes of patients with keratoconus. J Refract Surg. 2018;34(4):254259. doi:10.3928/1081597X-20180124-01

2. Hick S, Laliberte J-F, Meunier J, Chagnon M, Brunette I. Effects of misalignment during corneal topography. $J$ Cataract Refract Surg. 2007;33(9):1522-1529. doi:10.1016/j.jcrs.2007.05.029

3. Lang G, Holbach L, Schlotzer U. Pseudokeratoconus associated with Downs-Syndrome and posterior polymorphous corneal-dystrophy. Klin Monatsbl Augenh. 1989;195(2):95-99. doi:10.1055/s-2008-1046421

4. Hubbe R, Foulks G. The effect of poor fixation on computer-assisted topographic corneal analysis - Pseudokeratoconus. Ophthalmology. 1994;101(10):1745-1748. doi:10.1016/s0161-6420(94)31109-2
5. Dursun D, Piniella A, Pflugfelder S. Pseudokeratoconus caused by rosacea. Cornea. 2001;20(6):668-669. doi:10.1097/00003226-20010800000024

6. Cheng H-C, Lin -K-K, Chen Y-F, Hsiao C-H. Pseudokeratoconus in a patient with soft contact lens-induced keratopathy: assessment with Orbscan I. J Cataract Refract Surg. 2004;30(4):925-928. doi:10.1016/j. jers.2003.08.016

7. Reinstein DZ, Gobbe M, Archer TJ, Silverman RH, Coleman DJ. Epithelial, stromal, and total corneal thickness in keratoconus: three-dimensional display with artemis very-high frequency digital ultrasound. J Refract Surg. 2010;26(4):259-271. doi:10.3928/ 1081597X-20100218-01

8. Kanellopoulos AJ, Asimellis G. OCT corneal epithelial topographic asymmetry as a sensitive diagnostic tool for early and advancing keratoconus. Clin Ophthalmol (Auckland NZ). 2014;8:2277-2287. doi:10.2147/OPTH.S67902

9. Pircher N, Schwarzhans F, Holzer S, et al. Distinguishing keratoconic eyes and healthy eyes using ultrahigh-resolution optical coherence tomography-based corneal epithelium thickness mapping. Am J Ophthalmol. 2018;189:47-54. doi:10.1016/j.ajo.2018. 02.006

10. Reinstein DZ, Archer TJ, Gobbe M. Corneal epithelial thickness profile in the diagnosis of keratoconus. J Refract Surg. 2009;25 (7):604-610.

11. Collins MJ, Buehren T, Trevor $\mathrm{T}$, Statham M, Hansen J, Cavanagh DA. Factors influencing lid pressure on the cornea. Eye Contact Lens. 2006;32(4):168-173. doi:10.1097/01.icl.000 0189193.28870.81

12. De Paiva CS, Harris LD, Pflugfelder SC. Keratoconus-like topographic changes in keratoconjunctivitis sicca. Cornea. 2003;22(1):22-24.

13. Limpas Y, Schauer P, Vignal R, Wary P. [Oedema with acute pseudokeratoconus corneal aspect in a case of Kearns-Sayre syndrome]. $J$ Fr Ophtalmol. 2009;32(8):577.e1-5. doi:10.1016/j. jfo.2009.04.027

14. Kanellopoulos AJ, Asimellis G. In vivo three-dimensional corneal epithelium imaging in normal eyes by anterior-segment optical coherence tomography: a clinical reference study. Cornea. 2013;32 (11):1493-1498. doi:10.1097/ICO.0b013e3182a15cee

15. Wu Y, Wang Y. Detailed distribution of corneal epithelial thickness and correlated characteristics measured with SD-OCT in myopic eyes. J Ophthalmol. 2017;2017:1018321. doi:10.1155/ 2017/1018321

16. Hashmani N, Hashmani S, Saad CM. Wide corneal epithelial mapping using an optical coherence tomography. Invest Ophthalmol Vis Sci. 2018;59(3):1652-1658. doi:10.1167/iovs. 17-23717

17. Li Y, Tan O, Brass R, Weiss JL, Huang D. Corneal epithelial thickness mapping by Fourier-domain optical coherence tomography in normal and keratoconic eyes. Ophthalmology. 2012;119(12):24252433. doi:10.1016/j.ophtha.2012.06.023

18. Li Y, Chamberlain W, Tan O, Brass R, Weiss JL, Huang D. Subclinical keratoconus detection by pattern analysis of corneal and epithelial thickness maps with optical coherence tomography. $J$ Cataract Refract Surg. 2016;42(2):284-295. doi:10.1016/j. jcrs.2015.09.021

19. Rocha KM, Perez-Straziota CE, Perez-Straziota E, Stulting RD, Randleman JB. SD-OCT analysis of regional epithelial thickness profiles in keratoconus, postoperative corneal ectasia, and normal eyes. J Refract Surg. 2013;29(3):173-179. doi:10.3928/1081597X20130129-08

20. Wagner H, Barr JT, Zadnik K. Collaborative Longitudinal Evaluation of Keratoconus (CLEK) Study: methods and findings to date. Contact Lens Anterior Eye. 2007;30(4):223-232. doi:10.1016/j.clae.2007.03.001

21. Cui X, Hong J, Wang F, et al. Assessment of corneal epithelial thickness in dry eye patients. Optom Vis Sci Off Publ Am Acad Optom. 2014;91(12):1446-1454. doi:10.1097/OPX.0000000000000417 
22. Francoz M, Karamoko I, Baudouin C, Labbé A. Ocular surface epithelial thickness evaluation with spectral-domain optical coherence tomography. Invest Ophthalmol Vis Sci. 2011;52(12):91169123. doi:10.1167/iovs.11-7988

23. Tang M, Li Y, Chamberlain W, Louie DJ, Schallhorn JM, Huang D. Differentiating keratoconus and corneal warpage by analyzing focal change patterns in corneal topography, pachymetry, and epithelial thickness maps. Invest Ophthalmol Vis Sci. 2016;57(9):OCT544549. doi:10.1167/iovs.15-18938
24. Wu P, Cortes D, Li J, Chen M, Mannis M. Epithelial basement membrane dystrophy: a study with in vivo confocal microscopy and high-resolution anterior segment optical coherence tomography. Invest Ophthalmol Vis Sci. 2013;54(15):564.

25. Diez-Feijóo E, Durán JA. Optical coherence tomography findings in recurrent corneal erosion syndrome. Cornea. 2015;34(3):290-295. doi:10.1097/ICO.0000000000000334

\section{Publish your work in this journal}

Clinical Ophthalmology is an international, peer-reviewed journal covering all subspecialties within ophthalmology. Key topics include: Optometry; Visual science; Pharmacology and drug therapy in eye diseases; Basic Sciences; Primary and Secondary eye care; Patient Safety and Quality of Care Improvements. This journal is indexed on PubMed

Submit your manuscript here: https://www.dovepress.com/clinical-ophthalmology-journal
Central and CAS, and is the official journal of The Society of Clinical Ophthalmology (SCO). The manuscript management system is completely online and includes a very quick and fair peer-review system, which is all easy to use. Visit http://www.dovepress.com/ testimonials.php to read real quotes from published authors. 